\title{
Tobacco use induces anti-apoptotic, proliferative patterns of gene expression in circulating leukocytes of Caucasian males Peter C Charles ${ }^{\dagger 1,2}$, Brian D Alder ${ }^{\dagger 3}$, Eleanor G Hilliard ${ }^{1}$, Jonathan C Schisler ${ }^{1}$, Robert E Lineberger ${ }^{1}$, Joel S Parker ${ }^{4}$, Sabeen Mapara ${ }^{1}$, Samuel S Wu ${ }^{2}$, Andrea Portbury ${ }^{1}$, Cam Patterson ${ }^{*}+1,2$ and George A Stouffer ${ }^{\dagger 1,2}$
}

\begin{abstract}
Address: ${ }^{1}$ Carolina Cardiovascular Biology Center, University of North Carolina at Chapel Hill, Chapel Hill, USA, ${ }^{2}$ Division of Cardiology, School of Medicine, University of North Carolina at Chapel Hill, Chapel Hill, USA, ${ }^{3}$ School of Medicine, Duke University, Durham, USA and ${ }^{4}$ Expression Analysis Inc., Durham, USA

Email: Peter C Charles - pcharles@med.unc.edu; Brian D Alder - bdalder@gmail.com; Eleanor G Hilliard - eleanorh@med.unc.edu; Jonathan C Schisler - jonathan_schisler@med.unc.edu; Robert E Lineberger - rob_lineberger@med.unc.edu;

Joel S Parker - jparker@expressionanalysis.com; Sabeen Mapara - sabeen.mapara@gmail.com; Samuel S Wu - ssw@med.unc.edu; Andrea Portbury - andrea_portbury@med.unc.edu; Cam Patterson* - cpatters@med.unc.edu; George A Stouffer - rick_stouffer@med.unc.edu

* Corresponding author †Equal contributors
\end{abstract}

Published: 18 August 2008

BMC Medical Genomics 2008, I:38 doi:10.1 186/1755-8794-I-38

This article is available from: http://www.biomedcentral.com/I755-8794/I/38

(c) 2008 Charles et al; licensee BioMed Central Ltd.

This is an Open Access article distributed under the terms of the Creative Commons Attribution License (http://creativecommons.org/licenses/by/2.0), which permits unrestricted use, distribution, and reproduction in any medium, provided the original work is properly cited.
Received: 14 January 2008

Accepted: 18 August 2008

\begin{abstract}
Background: Strong epidemiologic evidence correlates tobacco use with a variety of serious adverse health effects, but the biological mechanisms that produce these effects remain elusive.

Results: We analyzed gene transcription data to identify expression spectra related to tobacco use in circulating leukocytes of 67 Caucasian male subjects. Levels of cotinine, a nicotine metabolite, were used as a surrogate marker for tobacco exposure. Significance Analysis of Microarray and Gene Set Analysis identified 109 genes in 16 gene sets whose transcription levels were differentially regulated by nicotine exposure. We subsequently analyzed this gene set by hyperclustering, a technique that allows the data to be clustered by both expression ratio and gene annotation (e.g. Gene Ontologies).

Conclusion: Our results demonstrate that tobacco use affects transcription of groups of genes that are involved in proliferation and apoptosis in circulating leukocytes. These transcriptional effects include a repertoire of transcriptional changes likely to increase the incidence of neoplasia through an altered expression of genes associated with transcription and signaling, interferon responses and repression of apoptotic pathways.
\end{abstract}

\section{Background}

Gene expression profiling has become a powerful approach to the study of molecular pathophysiology and is a potentially useful diagnostic tool in multiple fields [1]. Oncologists have applied gene expression profiling to predict breast cancer aggressiveness [2], and microarraydriven approaches have been used to analyze cardiovascular diseases such as hypertension, heart failure, cardiac rejection, and atherosclerosis [3-5]. Ideally, gene expression profiling is performed on the specific cell type and 
tissue of interest, i.e. the tumor, myocardium, or atheroma. However, sampling target tissues from humans is often problematic, and data derived from tissues not routinely available to clinicians limits the diagnostic utility of this approach.

For the study of biological processes that involve an inflammatory response, gene expression profiles can be obtained from circulating leukocytes [6]. Due to the ease of sampling, gene expression profiling of circulating leukocytes has been applied to the study of cancer [7], atherosclerosis $[8,9]$, and systemic lupus erythematosus [10]. These studies demonstrate the utility of transcriptional analysis of peripheral blood in the study of disease states having a systemic, inflammatory component.

Tobacco use, whether by smoking or chewing, is associated with the development of many diseases. People who smoke more than 20 cigarettes per day have a 3-6 fold increased incidence of myocardial infarction [11] and increased overall rates of cardiovascular mortality compared to those who have never smoked [12]. The risk of developing lung cancer is 20 -fold increased in cigarette smokers [8], and smokers are at increased risk of developing chronic obstructive pulmonary disease, multiple cancers (e.g. esophageal, bladder, and leukemia), pneumonia, osteoporosis, and periodontal disease [13]. Despite these major adverse health effects, more than $20 \%$ of American adults identify themselves as active smokers [14].

The mechanistic link between tobacco smoking and related diseases remain incompletely understood. To date, there have been numerous reports analyzing the effect that exposure to cigarette smoke has on the gene expression profiles of various cell types [15-22]. However, despite this detailed analysis, very little consensus amongst findings has been reported, even when the same cell type has been studied [16]. This lack of significant overlap in conclusions may be the result of the considerable heterogeneity in methodology as well as the relatively small (on average 5-10 test subjects) sample populations in each study. Furthermore, many of these reports rely on the in vitro exposure of cells to cigarette smoke condensate, raising the obvious issue of physiological relevance amongst these various studies.

Here we report a novel method for analyzing the in vivo effects of tobacco use on gene expression in circulating leukocytes. The purpose of this study is not to identify biomarkers associated with tobacco use; rather, our approach is aimed at identifying changes in genes and gene sets that result from tobacco use and applying this information to identify potential cellular pathways associated with tobacco-dependent pathology. Our results indi- cate that tobacco use affects pathways that control cell death, response to stress, macromolecular metabolism and the inflammatory cascade, providing new insights into the systemic effects of smoking that may underlie tobacco-related diseases.

\section{Methods \\ Subject Population}

Subjects between the ages of 18 and 50 years (inclusive) referred to UNC Hospitals were considered for enrollment in this University of North Carolina Institutional Review Board-approved study (IRB 04-MED-471). Exclusion criteria included current cancer treatment, pregnancy, lymphoma, leukemia, chronic immunosuppressive therapy, infection with HIV or HCV, history of solid organ transplant, and anemia (i.e. conditions which might alter peripheral blood counts or patterns of gene expression). After obtaining informed consent for a one-time blood donation, subjects were interviewed for pertinent medical information, including a detailed history of tobacco use, family history of heart disease and diabetes. Blood cell counts including a white blood cell differential analysis was performed to ensure consistency in cell subtype number between study populations.

\section{Blood Withdrawal and Processing}

Blood (30 ml) was drawn early in the day from subjects fasted for at least 8 hours to minimize the signals associated with nutritional and diurnal cycles from the microarray data. Processing was begun within 15 minutes of the time of blood draw. Eight $\mathrm{ml}$ were collected into a tube containing EDTA and proteinase inhibitors (Becton, Dickinson and Co., Cockeysville, MD) to provide a sample of plasma for cotinine assays. The balance of blood was collected into Na-EDTA Vacutainer tubes (Becton, Dickinson and Co., Cockeysville, MD). Whole blood was treated with 10 volumes of carbonate-buffered $150 \mathrm{mM} \mathrm{NH}_{4} \mathrm{Cl}$ to lyse red blood cells. The remaining leukocytes were washed and concentrated by centrifugation $[23,24]$. RNA and DNA were recovered from leukocytes using a modified one-step acid guanidinium isothiocyanate-phenolchloroform extraction (RNA-STAT60, Tel-Test, TX). RNA was subsequently post-purified using the RNeasy Mini-kit (Qiagen, Valencia, CA). RNA quantity, purity, and integrity were assessed by spectrophotometry and microcapillary electrophoresis on an Agilent BioAnalyzer 2100. Complete processing of samples occurred within 2 hours, exceeding the standards set by the Consortium for Expression Profiles in Sepsis [25]. Plasma cotinine levels were determined by competitive ELISA using the Serum Cotinine Assay Kit (BioQuant; San Diego, CA) essentially as described by the manufacturer. 


\section{Gene Expression Profiling}

We utilized a "sample $\times$ reference" experimental design strategy in which RNA from each subject was hybridized to the microarray slide in the presence of labeled human reference RNA (UHRR, Stratagene, La Jolla, CA) [26,27]. Briefly, total RNA (500 ng) was used for gene expression profiling following reverse transcription and $\mathrm{T}-7$ polymerase-mediated amplification/labeling with Cyanine-5 CTP. Labeled subject cRNA was co-hybridized to Agilent G4112A Whole Human Genome 44 K oligonucleotide arrays with equimolar amounts of Cyanine-3 labeled UHRR. Slides were hybridized and washed, then scanned on an Axon 4000b microarray scanner. The data were processed using GenePix Pro 6 software and entered into the UNC Microarray Database [28].

\section{Quantitative Real Time Polymerase Chain Reaction (qRT- PCR) analysis}

Three hundred nanograms of total RNA were reverse transcribed using the iScript Synthesis cDNA Kit (Biorad, Hercules, CA). Real-time PCR reactions were performed using either the Roche Universal Probe Library (Roche Diagnostics, Mannheim, Germany) or pre-validated Taqman ${ }^{\circledR}$ assays (Applied Biosystems, Framingham, MA). Primers and probes for the indicated human transcripts were designed using Probe Finder (version 2.41, Roche Diagnostics, Mannheim, Germany): CDKN1C (left primer GAGCGAGCTAGCCAGCAG, right primer GCGACAAGACGCTCCATC, probe \#77); CX3CR1 (left primer CTCTGGCTTCTGGGTGGAG, right primer AGACCACGATGTCCCCAATA, probe \#30); SASH1 (left primer CAGATCCGGGTGAAGCAG, right primer GAGTCCACCACTTGGAATCG, probe \#38); RPS29 (left primer CCAAGAACTGCAAAGCCATC, right primer GGCATTGGTGACTCTGATGA, probe \#26); and $18 S$ (left primer GGAGAGGGAGCCTGAGAAAC, right primer TCGGGAGTGGGTAATTTGC, probe \#40). PTGDR and HRASLS3 were measured using Taqman ${ }^{\circledast}$ assays Hs00235003_m1 and Hs00272992_m1, respectively. Real-time PCR reactions were performed using the ABI PRISM $^{\circledR} 7900$ sequence detection system, software, and reagents. Relative changes in gene expression were calculated using the delta Ct method using ribosomal $18 \mathrm{~S}$ to normalize RNA input. Statistical significance was determined using the Student's $t$ test. $P$ values less than 0.05 were considered significant.

\section{Statistical Methods}

Microarray data were normalized via the loess local intensity normalization $[7,29]$, and probes were filtered for features having a normalized intensity of $<30$ aFU in either channel. Probes were removed if $<70 \%$ of the data were present across all samples. Missing data points were imputed using the k nearest-neighbors algorithm $(\mathrm{k}=10)$. 18,375 probes passed these filters, and were subsequently used for analysis. Scripts written in the R Statistical Language and Environment ("R"; Version 2.2.1, build r36812, release date 2005-12-20.) and Perl (ActiveState Perl 5.8.1, build 807, release date 2003-11-6) were used to standardize $(\mu=0, \sigma=1)$ each sample in the data set.

\section{Statistical Analysis of Microarrays (SAM)}

Lists of differentially expressed genes were identified using the statistical analysis of microarray algorithm [30-32] (SAM, Version 2.21, release date 2005-8-24; typical false discovery rate of approximately 10\%). Unsupervised, semi-supervised, and supervised clustering analysis was performed on gene lists essentially as described [33] using Cluster, version 2.11[34]. Heat maps of cluster analyses were visualized with JavaTreeView, version 1.0.12 [35,36].

\section{Gene Set Analysis (GSA)}

GSA $[37,38]$ was performed using the Molecular Signatures Database (MSigDB) [39] to identify gene set activity associated with cotinine levels. Mapping to gene ontology categories (GO) [40] and identification of putative transcription factor binding sites was performed on gene lists using the GATHER web-based analysis environment [4143] using the TRANSFAC V7.0 (public) database [44-47].

\section{Hyperclustering}

A median-centered gene list was used for cluster analysis to identify relationships between subject samples (arrays). The clustering file was then used as the basis for a new preclustering file to incorporate gene annotation data. Genes were assigned to GO and TRANSFAC categories using the GATHER web interface [42]. Categories showing statistical enrichment ( $\mathrm{p}$ value $<0.01$ ) were identified, and each gene in the pre-clustering file was annotated as to its membership in the appropriate category. The TRANSFAC predictions of transcription factor binding sites were designated in the pre-clustering file by the value representing the median-centered mean fold change expressed as the $\log _{2}$ of the ratio of each sample to the reference for each gene. This method of indicating membership was chosen to reflect a relationship between expression level (as measured by microarray) and presence or absence of transcription factor binding sites. Gene membership in GO categories was indicated by a binary value of either 1.00 or 0.00 as a placeholder for the expression ratio. Blue color was added after the fact to heat maps indicating Gene Ontology membership to avoid confusion with expression values. The annotated pre-clustering file was then clustered on only the Y axis (genes) to preserve relationships among arrays. This technique, which we have designated "Hyperclustering," allows both the gene expression data and various other forms of annotation to be represented as a single heat map, effectively illustrating functional relationships among genes. 


\section{Results and discussion Subject Selection for Gene Expression Analysis}

Initial analysis of the gene transcription data from a cohort of 171 individuals revealed strong signals related to the race and gender of the subject (unpublished observations). Similar signals have been described in other microarray experiments. These signals can hinder attempts to identify signals related to the biological effect being studied [48]. For this reason, we selected the largest cohort in our dataset (Caucasian males) to maximize the statistical power of our analysis. We adopted a case-control approach to our study design and data analysis. Selected subject demographics are presented in Table 1.

\section{Tobacco Use Determination}

Self-reported tobacco use history is notoriously inaccurate [49-51]. For purposes of this study, we defined tobacco use status by the subject's plasma cotinine concentration. Cotinine, the principle metabolite of nicotine, is a reliable surrogate marker of tobacco use [52,53]. It has a plasma half-life of approximately 24 hours (as opposed to nicotine's in vivo half-life of 30 minutes) and tends to reach steady state levels that vary by only $15 \%-20 \%$ in people with regular smoking habits [52]. As seen in Figure 1, the distribution of plasma cotinine is similar in both the Caucasian male subpopulation under study and a larger cohort of 171 subjects, with strong bimodal peaks near 0 $\mathrm{ng} / \mathrm{mL}$ and $150 \mathrm{ng} / \mathrm{mL}$. Cutoffs of plasma cotinine for the definition of active tobacco users and non-users were set at $>100 \mathrm{ng} / \mathrm{mL}$ and $<50 \mathrm{ng} / \mathrm{mL}$, respectively, based on previously reported values $[52,53]$.
Using these criteria, 24 subjects were classified as tobacco users and 38 as non-tobacco users, with 5 subjects having cotinine levels that fell between 50 and $100 \mathrm{ng} / \mathrm{mL}$. These 5 intermediate subjects were removed from further consideration. Comparing each subject's plasma cotinine values with their self-reported tobacco use status revealed overall consistent results (i.e. a high cotinine value for subjects who self-reported that they were active tobacco users). Nevertheless, there were notable exceptions. Seven subjects reported that they were non-tobacco users, yet had plasma cotinine levels > $100 \mathrm{ng} / \mathrm{mL}$. Errors in this dimension could be explained by subject misrepresentation or failure of the subjects to disclose nicotine replacement therapy as part of a smoking cessation plan (use of nicotine patches or gum). Interestingly, 3 subjects identified themselves as active smokers, yet had very low plasma cotinine levels. Rapid metabolism of nicotine, smoking of a small number of cigarettes daily, or the use of extremely low-nicotine smoking products could all account for this discrepancy. This discrepancy in self-reported tobacco use and plasma cotinine levels did not appreciably alter the results of our studies (data not shown). All subjects were categorized based only on plasma cotinine levels only. The 2 subject groups will henceforth be referred to as "high cotinine" (i.e. tobacco users) and "low cotinine" (i.e. non-tobacco users). Using this criterion, those subjects reporting to be "smokers" but who had low plasma cotinine levels were included in the low cotinine group while subjects with high cotinine levels who denied smoking were included in the high cotinine group. To ensure that patient co-morbidities did not influence the gene expression profile, we performed principal components analysis (PCA) on the expression values of genes

Table I: Selected demographics of study subjects.

\begin{tabular}{|c|c|c|c|}
\hline & & Low Cotinine & High Cotinine \\
\hline Number of subjects & & 38 & 24 \\
\hline Mean Age $\pm S D$ & & $47 \pm 9$ & $46 \pm 5$ \\
\hline COPD & & $2(5.3 \%)$ & $4(16.7 \%)$ \\
\hline \multirow[t]{3}{*}{ Diagnosis of Diabetes (Number (\% of total)) } & *Any & $13(34 \%)$ & $2(8.3 \%)$ \\
\hline & Type I & $2(5 \%)$ & I (4\%) \\
\hline & Type 2 & II (29\%) & I (4\%) \\
\hline CAD Family History & & $20(53 \%)$ & $15(63 \%)$ \\
\hline Hyperlipidemia & & $24(63 \%)$ & $16(67 \%)$ \\
\hline \multirow[t]{7}{*}{ Automated Differential Blood Count } & White Blood Cells $\left(\times 10^{9} / L \pm S D\right)$ & $8.42 \pm 2.67$ & $9.00 \pm 2.41$ \\
\hline & Neutrophils $\left(\times 10^{9} / \mathrm{L} \pm \mathrm{SD}\right)$ & $5.67 \pm 2.18$ & $5.76 \pm 1.94$ \\
\hline & Lymphocytes $\left(\times 10^{9} / \mathrm{L} \pm \mathrm{SD}\right)$ & $1.90 \pm 0.68$ & $2.31 \pm 0.74$ \\
\hline & Monocytes (× 109/L $\pm \mathrm{SD})$ & $0.42 \pm 0.18$ & $0.46 \pm 0.21$ \\
\hline & Basophils $\left(\times 10^{9} / \mathrm{L} \pm \mathrm{SD}\right)$ & $0.06 \pm 0.04$ & $0.06 \pm 0.04$ \\
\hline & Eosinophils $\left(\times 10^{9} / \mathrm{L} \pm \mathrm{SD}\right)$ & $0.22 \pm 0.18$ & $0.26 \pm 0.14$ \\
\hline & Platelets (× 109/L $\pm S D)$ & $252.42 \pm 73.97$ & $250.67 \pm 56.06$ \\
\hline
\end{tabular}

$\mathrm{CAD}=$ Coronary Artery Disease, $\mathrm{SD}=$ Standard Deviation, $\mathrm{L}=$ liter, $\mathrm{fL}=$ femtoliter, $\mathrm{dL}=$ deciliter, $\mathrm{G}=$ gram, $\mathrm{pG}=$ picogram, $\mathrm{COPD}=\mathrm{Chronic}$ Obstructive Pulmonary Disease. For Student's T-test, automated cell counting values were recalculated as values per gram or liter, and log2 normalized prior to determination of $\mathrm{p}$-Value.

* Fisher's Exact Test shows significant differences between low and high cotinine at $p=0.0315$ (2-tail) 


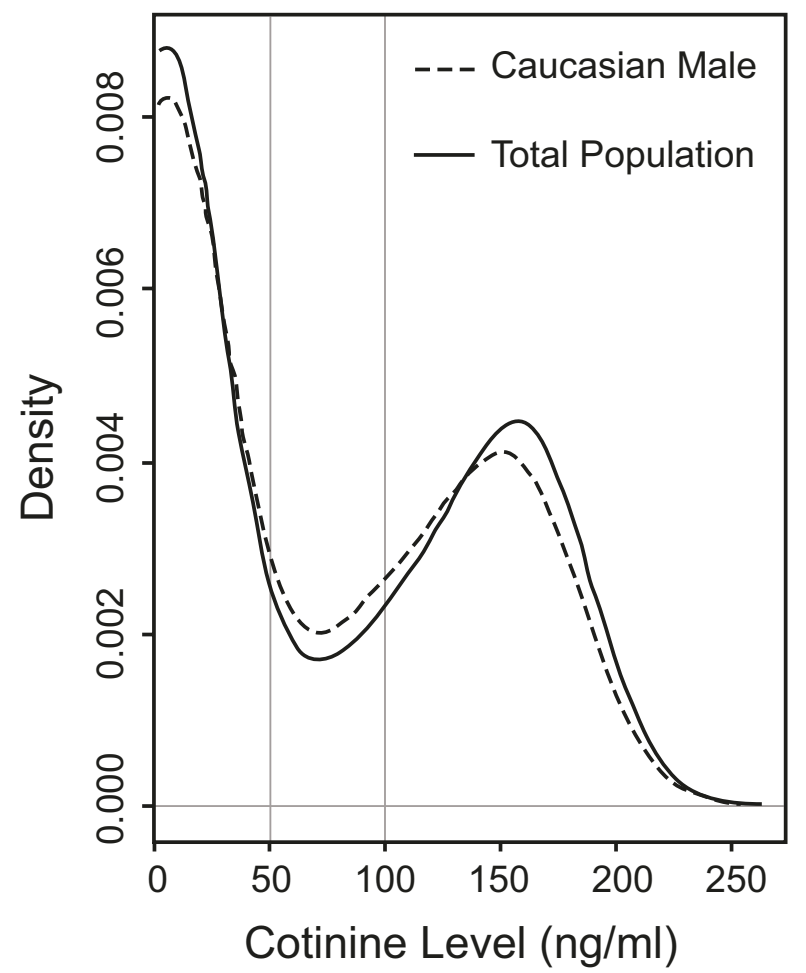

Figure I

Histogram of plasma cotinine concentration. Distribution of plasma cotinine levels in the total population as well as in the Caucasian male sub-population are demonstrated. Vertical lines represent selected cut-offs for definitions of tobacco users and non-users.

identified in this paper using the combined significant gene list and visualized in the context of COPD, diabetes, CAD class, and smoking status (Additional File 1). As expected, the top component of variation appears to be associated only with smoking status.

\section{Transcriptional Signals of Tobacco Use}

The subjects were stratified based upon the results of the cotinine assay, and differential gene expression was determined by SAM. We identified 38 genes as being differentially expressed ( 8 genes up-regulated, 30 genes downregulated in the high-cotinine group) at an $11.7 \%$ FDR (Table 2). Notable among this list were genes involved in apoptosis, cell cycle regulation, and oncogenesis.

Visual inspection of the SAM-identified genes revealed that a number of differentially expressed genes are involved in the cell cycle control Gene Ontologies. CTCF was down regulated in the high cotinine group. Mutations in this gene have been associated with a variety of cancers [54]. Furthermore, CTCF plays an important role in the regulation and differentiation of human myeloid leukemia cells, adding another possible underlying mechanism of leukemiagenesis in tobacco users [55]. Conversely, we found that SASH1 (which is implicated in tumorogenesis of colorectal and breast cancer) was up regulated [56]. Interestingly, CX3CR1 was significantly down regulated in the high cotinine group. As CX3CR1 is up-regulated in atherosclerotic lesions [57], we expected it to be up-regulated in circulating leukocytes of tobacco users due to the increased incidence and severity of CAD in this population (reviewed by Njolstad [11]). However, Barlic, et al., showed that macrophage up-regulation of CX3CR1 leads to retention of those cells in vessel walls [57]. As the kinetics of the up-regulation of this gene are ill-defined, and it is not yet clear whether circulating monocytes differentially express CX3CR1 prior to tissue macrophage transformation, considerably more study will be necessary to elucidate what role it may play in the pathogenesis of smoking-related atherosclerotic disease.

Further analysis identified genes involved in apoptotic pathways. The pro-apoptotic genes C1D, MTCBP-1, CTCF, $I K I P, M A F$, and YWHAQ were all significantly down regulated in the high cotinine group. C1D (also known as SUNCOR) is representative of this group. C1D is a multifunctional nuclear protein with DNA-binding properties. When $C 1 D$ is experimentally over-expressed it activates $D N A-P K$, inducing apoptosis [58]. On the other hand, the c-terminal modulator protein (CTMP, also known as THEM4) was significantly over-expressed in the high cotinine population. CTMP protein stimulates the phosphorylation of $\mathrm{AKT} / \mathrm{PKB}$, increasing glucose uptake and blocking apoptosis [22]. The relative mean fold change was modest for most of these genes (Table 2); nevertheless, in subjects with high plasma cotinine the overall expression pattern of these genes is anti-apoptotic compared to low cotinine subjects. The combination of increased cell cycle activity, resistance to apoptotic triggers, increased expression of oncogenes, and decreased expression of tumor suppressor genes in circulating leukocytes suggests a mechanism responsible for the low-level, systemic, increased risk of oncogenesis in patients who use tobacco products.

Testing for differential expression of individual genes does not take advantage of our knowledge of the underlying relationships. Therefore, additional power can be gained by testing for differential expression of gene sets that underlie a common biological process $[37,38,59]$. This idea motivated the development of techniques that pair local statistics of individual gene expression with global statistics based on membership in defined pathways and functional groups. One such algorithm, Gene Set Analysis (GSA), was implemented using the Molecular Signatures database (MSigDB). The GSA algorithm identified 16 gene sets at a p-value $<0.0001$ and FDR of $0 \%$. The top three MSigDB pathways were "Death Pathway," 
Table 2: Differentially expressed genes identified by SAM analysis.

\begin{tabular}{|c|c|c|c|c|}
\hline \multicolumn{5}{|c|}{ Down-regulated in High Cotinine Subjects } \\
\hline Gene Symbol & Gene Name & Accession Number & Agilent Probe ID & Mean FC \\
\hline HRASLS3 & HRAS-like suppressor 3 & NM 007069 & A_23_PII64I4 & 1.5 \\
\hline CX3CRI & Chemokine (C-X3-C motif) receptor I & NM 001337 & A_23_P407565 & 1.3 \\
\hline GPR56 & G protein-coupled receptor 56 & NM 005682 & A_23_P206280 & 1.3 \\
\hline PTGDS & Prostaglandin D2 synthase 2 I kDa (brain) & NM 000954 & A_23_PI46554 & 1.3 \\
\hline FLJ23262 & & $\underline{\mathrm{BC} 043173}$ & A_24_P20996 & 1.2 \\
\hline BRDI & Bromodomain containing I & NM 014577 & A_23_PI66536 & 1.2 \\
\hline BZRAPI & Benzodiazapine receptor (peripheral) associated protein I & NM 004758 & A_23_PI52559 & 1.2 \\
\hline CID & Nuclear DNA-binding protein & NM 173177 & A_23_P67992 & 1.2 \\
\hline FLJ23262 & & $\overline{\mathrm{BC} 043173}$ & A_24_P20996 & 1.2 \\
\hline CTCF & CCCTC-binding factor (zinc finger protein) & NM 006565 & A_24_P347704 & 1.2 \\
\hline DNAJB6 & DnaJ (Hsp40) homolog, subfamily B, member 6 & NM 058246 & A_24_P63827 & 1.2 \\
\hline ENST00000320343 & & ENSG00000177197 & A_24_P75688 & 1.2 \\
\hline FLJ35696 & & NM 207387 & A_23_P368484 & 1.2 \\
\hline GNG2 & Guanine nucleotide binding protein ( $\mathrm{G}$ protein), gamma & NM 053064 & A_32_P208403 & 1.2 \\
\hline HS6STI & Heparan sulfate 6-O-sulfotransferase I & $\underline{\mathrm{AL} 831893}$ & A_24_P8220 & 1.2 \\
\hline IKIP & IKK interacting protein & NM 201613 & A_23_P53467 & 1.2 \\
\hline KLRKI & Killer cell lectin-like receptor subfamily K, member I & NM 007360 & A_23_P218058 & 1.2 \\
\hline MAF & $\begin{array}{l}\text { V-maf musculoaponeurotic fibrosarcoma oncogene homolog } \\
\text { (avian) }\end{array}$ & $\underline{\text { AF055376 }}$ & A_24_P256219 & 1.2 \\
\hline MGC6I57I & & NM 182523 & A_24_P408740 & 1.2 \\
\hline MTCBP-I & $\begin{array}{l}\text { Membrane-type I matrix metalloproteinase cytoplasmic tail } \\
\text { binding protein-I }\end{array}$ & NM 018269 & A_23_PI48I94 & 1.2 \\
\hline$\underline{A L I 37798}$ & & NM 032723 & A_23_PI26486 & 1.2 \\
\hline OSBPL5 & Oxysterol binding protein-like 5 & NM 145638 & A_23_P5308I & 1.2 \\
\hline PPPICB & Protein phosphatase I, catalytic subunit, beta isoform & NM 206877 & A_23_P834I4 & 1.2 \\
\hline PPPIRI2B & Protein phosphatase I, regulatory (inhibitor) subunit I2B & NM 00248I & A_23_P20I790 & 1.2 \\
\hline PPP2R2B & $\begin{array}{l}\text { Protein phosphatase } 2 \text { (formerly } 2 A \text { ), regulatory subunit B (PR } \\
52 \text { ), beta isoform }\end{array}$ & NM 181678 & A_23_P213620 & 1.2 \\
\hline SLC25A20 & $\begin{array}{l}\text { Solute carrier family } 25 \text { (carnitine/acylcarnitine translocase), } \\
\text { member } 20\end{array}$ & NM 000387 & A_23_P72025 & 1.2 \\
\hline SLC9A3RI & $\begin{array}{l}\text { Solute carrier family } 9 \text { (sodium/hydrogen exchanger), isoform } 3 \\
\text { regulator I }\end{array}$ & NM 004252 & A_23_P3085I9 & 1.2 \\
\hline SULF2 & Sulfatase 2 & NM 198596 & A_23_PI54605 & 1.2 \\
\hline YWHAQ & $\begin{array}{l}\text { Tyrosine 3-monooxygenase/tryptophan 5-monooxygenase } \\
\text { activation protein, theta polypeptide }\end{array}$ & NM 006826 & A_24_PI99905 & 1.2 \\
\hline PTGDR & Prostaglandin D2 receptor (DP) & NM 000953 & A_23_P393777 & 1.1 \\
\hline \multicolumn{5}{|c|}{ Up-regulated in High Cotinine Subjects } \\
\hline Gene Symbol & Gene Name & Accesion Number & Agilent Probe ID & Mean FC \\
\hline SASHI & SAM and $\mathrm{SH} 3$ domain containing $\mathrm{I}$ & NM 015278 & A_23_P93442 & 1.4 \\
\hline$\underline{\mathrm{BC} I 07798}$ & & NM 003283 & A_23_P56050 & 1.4 \\
\hline$\underline{A L 442066}$ & & $\underline{A L 442066}$ & A_23_PI23645 & 1.3 \\
\hline DNAPTP6 & DNA polymerase-transactivated protein 6 & NM 015535 & A_23_PI3I255 & 1.3 \\
\hline CIGALTI & $\begin{array}{l}\text { Core I UDP-galactose:N-acetylgalactosamine-alpha-R beta I,3- } \\
\text { galactosyltransferase }\end{array}$ & NM 020156 & A_23_P252I45 & 1.2 \\
\hline RGLI & Ral guanine nucleotide dissociation stimulator-like I & $\underline{N M 015149}$ & A_23_PII54I7 & 1.2 \\
\hline CTMP & C-terminal modulator protein & NM 176853 & A_23_PI49375 & 1.2 \\
\hline LOC283I74 & Hypothetical protein LOC283I74 & NM 001001873 & A_24_P904484 & 1.2 \\
\hline
\end{tabular}

"Dac_IFN_Bladder_Up,"

and

"Metastasis_Adenocarcinoma" (Table 3). Although many of the genes comprising these sets did not reach statistical significance individually, taken as a group they were highly significant. Genes related to apoptosis and type I interferon response were common elements in all of these pathways. Among genes involved in the MSigDB "Death Pathway," expression of BIRC3 and TRAF2 (anti-apop- totic genes) were up regulated while CASP9, FADD, and STK17A (pro-apoptotic genes) were down regulated in the high cotinine group. This overall expression pattern is indicative of an anti-apoptotic phenotype, which characterizes virtually all cancers. These observations suggest that transcriptional profiles associated with tobacco use may indicate pre-cancerous tendencies. The 71 genes present in the top 3 pathways (Table 3 ) were added to the 
Table 3: Summary of GSA.

\begin{tabular}{|c|c|c|c|}
\hline Gene Set Pathway & Description & P-value & FDR \\
\hline DEATHPATHWAY (c2:16I)[7I] & Genes involved in signaling via Fas and DR3, 4, and 5. & $<0.0001$ & 0 \\
\hline METASTASIS_ADENOCARC_DN (c2:1553)[72] & Genes involved in metastasis of solid tumors. & $<0.0001$ & 0 \\
\hline DAC_IFN_BLADDER_UP (c2:1304)[73] & Interferon responsive genes upregulated by DAC treatment. & $<0.0001$ & 0 \\
\hline
\end{tabular}

Top 3 gene sets (7I total genes) identified by GSA comparing gene expression profiles of subjects with high plasma cotinine versus low plasma cotinine, showing the names of differentially expressed gene sets as defined by Gene Set Enrichment Analysis [70] with accompanying P-value and FDR.

list of 38 SAM-identified genes to enrich the gene list that was used for further analysis. This list of 109-pooled genes is available as Additional file 2.

\section{Pattern Identification via the Hyperclustering Technique} Differentially expressed genes were hyperclustered (see Materials and Methods) and visualized (Figure 2) using the pooled gene list. The subjects with the highest mean levels of cotinine were clearly separated from the subjects with the lowest mean cotinine levels using this technique. Moreover, genes were clustered into functional groups based on their expression patterns, membership in Gene Ontologies (Table 4, labeled A-G), and presence of predicted transcription factor binding sites. This produced 5 physiologically relevant clusters. The 'Stress' cluster is comprised of stress-responsive genes involved in signal transduction (CX3CR1 and ITGB1). The 'Macromolecular Metabolism' cluster is made up of metabolic genes (HIPK1, SUMO2, SULF2, and FKBP3). The third cluster, 'Transcription and Signaling', contains genes associated primarily with $\mathrm{G}$ protein signaling and transcriptional regulation (RASGEF1A, RAB2, ARHGAP1, PPP1R12B, CREBBP, and GNG2). 'Cell Death and Apoptosis' is a cluster of genes associated with apoptosis and its regulation. The fifth cluster, 'Interferon' is defined by genes that potentially contain an interferon-stimulated response element-binding site or are responsive to type-1 interferons.

The utility of the hyperclustering technique is readily apparent: a single image indicates the relationships among the genes, lending physiological relevance to a data set. A case in point is the 'Interferon' cluster, comprised of genes that are strongly up regulated in approximately half of the subjects with the highest cotinine levels. The genes in this cluster (IFI44, IFIT1, USP18, and HERC5. Figure 2) are interferon responsive genes, and are members of the gene class forming the early response to type-I interferons, indicative of a cellular response to viral agents or very specific forms of genotoxicity. Our findings are consistent with those of Grumelli, et al. who demonstrated that lymphocytes isolated from lung samples of patients with smoking-related lung damage showed an increase in expression of multiple interferon-inducible proteins [60]. These results indicate that induction of interferon-dependent transcription pathways appear sys- temically in some tobacco users. Only half of the tobacco users have this expression pattern; the mechanisms of which are unknown, but worthy of future investigation. It is tempting to speculate that these patterns of systemic interferon-responsive induction identify a group of tobacco users who may develop early and severe disease. Longitudinal studies designed to track the patterns of gene expression over time in cohorts of tobacco users and nonusers will be necessary to unambiguously determine the meaning of these observations.

\section{Real time PCR verification of differentially expressed genes}

Quantitative real time PCR was used for both technical (microarray) and biological verification. Four genes selected from SAM and one gene from GSA: CX3CR1, SASH1, HRASLS3, PTGDR, and CDKN1C, respectively, were used for technical verification (Figure 3, left panel) on samples randomly selected from the low and high cotinine subject population (Caucasian males). The up or down regulation of these genes, irrespective of their method of identification (SAM or GSA) was consistent with the microarray analysis. Furthermore, the relative fold changes determined via quantitative real time PCR were either equal to or greater than the fold change measured by the microarray analysis, and significantly different between the low and high cotinine subjects $(P<0.05)$. Analysis using subjects excluded from the microarray analysis (Caucasian females) biologically validated the cotinine-dependent change in expression of two genes, CDKN1C and SASH1 (Figure 3, right panel). RPS29 was used as a negative control gene and was not found to be differentially expressed either by microarray or real time PCR analysis.

\section{Conclusion}

In this study we demonstrated that groups of genes in circulating human leukocytes are affected by tobacco use in vivo. We identified genes and their relationships using a combination of testing individual genes (SAM), testing gene sets (GSA), and high throughput annotation (GATHER). Hyperclustering using Gene Ontologies and transcription factor binding sites associated with these genes illuminated the functional significance of the differentially regulated genes. The resulting gene expression 


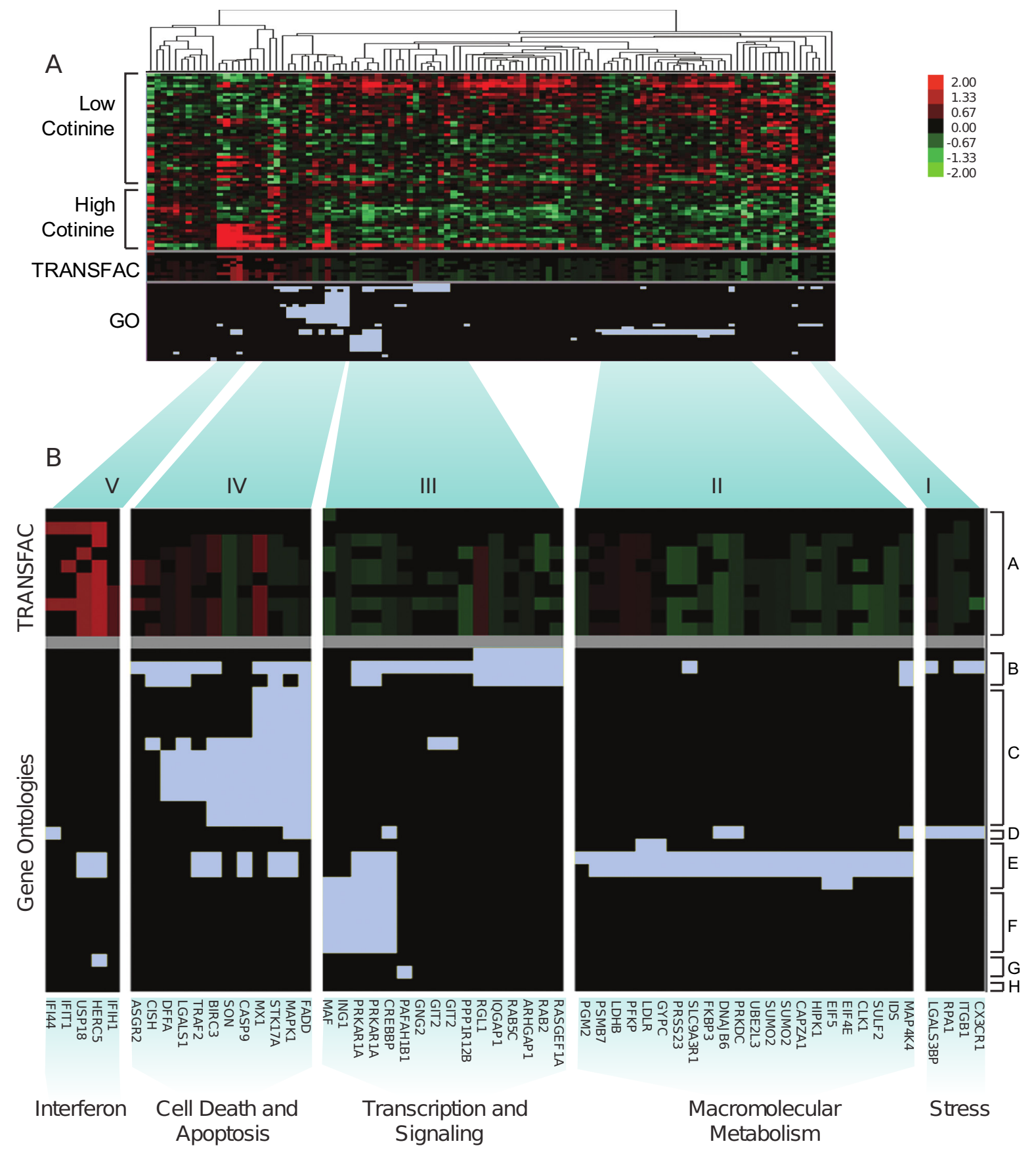

\section{Figure 2}

Hyperclustering of cotinine responsive genes. A. The 109 genes identified by SAM and GSA analysis in subjects with high versus low plasma cotinine levels were analyzed by hyperclustering. Clusters (top) were created by incorporating gene expression data with their corresponding TRANSFAC and Gene Ontology (GO) categories. Genes are represented in columns. Individual subject expression profiles (which clustered into 2 groups, high and low cotinine) and TRANSFAC categories are represented in rows and the relative expression of the genes is reflected as indicated in the color scale (upper right). Gene membership in GO categories (also represented in rows) is indicated by Carolina blue. B. Enlargement of the five functional groups identified by hyperclustering (bottom). The corresponding TRANSFAC and GO categories are indicated by groups $A$ and B-H, respectively (see Table 4 for detailed category information). 
Table 4: Hyperclustered TRANSFAC and GO Category Annotations

\begin{tabular}{|c|c|c|c|c|}
\hline Cluster & TRANSFAC Annotations & & & \\
\hline \multirow[t]{10}{*}{ A } & V\$POU3F2_02 & & & \\
\hline & V\$ISRE_0I: interferon-stimulated response element & & & \\
\hline & V\$DEAFI_0I & & & \\
\hline & V\$E2FI_Q3_0I & & & \\
\hline & V\$MAZR_0I: MAZ related factor & & & \\
\hline & V\$KROX_Q6 & & & \\
\hline & V\$E2FIDPI_0I: E2F-I:DP-I heterodimer & & & \\
\hline & V\$HNFI_Q6 & & & \\
\hline & V\$E2F_Q3_0I & & & \\
\hline & V\$E2FI_Q6: E2F-I & & & \\
\hline Cluster & Common GO Parent Node & Gene Ontology & GO Level & GO Name \\
\hline \multirow[t]{3}{*}{ B } & signal transduction [4] GO:0007। 65 & GO:0007264 & 6 & small GTPase mediated signal transduction \\
\hline & & GO:0007I65 & 4 & signal transduction \\
\hline & & GO:0007242 & 5 & intracellular signaling cascade \\
\hline \multirow[t]{11}{*}{ C } & programmed cell death [5] GO:00I250I & GO:0006917 & 8 & induction of apoptosis \\
\hline & & GO:001 2502 & 7 & induction of programmed cell death \\
\hline & & GO:0043068 & 6 & positive regulation of programmed cell death \\
\hline & & GO:0043065 & 7 & positive regulation of apoptosis \\
\hline & & GO:0050794 & $3^{*}$ & regulation of cellular process \\
\hline & & GO:0016265 & $3^{*}$ & death \\
\hline & & GO:0008219 & $4^{*}$ & cell death \\
\hline & & GO:0012501 & 5 & programmed cell death \\
\hline & & GO:0006915 & 6 & apoptosis \\
\hline & & GO:0043067 & 5 & regulation of programmed cell death \\
\hline & & GO:004298I & 6 & regulation of apoptosis \\
\hline $\mathrm{D}$ & response to stress [4] GO:0006950 & GO:0006950 & 4 & response to stress \\
\hline \multirow[t]{4}{*}{$\mathrm{E}$} & macromolecule metabolic process [4] GO:0043I 70 & GO:0006493 & 9 & O-linked glycosylation \\
\hline & & GO:0043170 & 4 & macromolecule metabolism \\
\hline & & GO:0044260 & 5 & cellular macromolecule metabolism \\
\hline & & GO:0019222 & $4^{*}$ & regulation of metabolism \\
\hline \multirow[t]{5}{*}{$\mathrm{F}$} & transcription [6] GO:0006350 & GO:0006350 & 6 & transcription \\
\hline & & GO:0045449 & 6 & regulation of transcription \\
\hline & & GO:0019219 & $5^{*}$ & $\begin{array}{l}\text { regulation of nucleo-base, -side, -tide and nucleic } \\
\text { acid metabolism }\end{array}$ \\
\hline & & GO:0006355 & 7 & regulation of transcription, DNA-dependent \\
\hline & & GO:000635I & 7 & transcription, DNA-dependent \\
\hline \multirow[t]{2}{*}{ G } & cell cycle process [6] GO:0022402 & GO:0000082 & 7 & $\mathrm{GI} / \mathrm{S}$ transition of mitotic cell cycle \\
\hline & & GO:0000132 & 11 & mitotic spindle orientation \\
\hline $\mathrm{H}$ & mevalonate transport [8] GO:0015728 & GO:0015728 & 8 & mevalonate transport \\
\hline
\end{tabular}

* Node is not a child of the parent node for this group

spectra revealed novel and under-recognized molecular pathways in the pathophysiology of diseases commonly associated with tobacco use. Genomic signals in circulating leukocytes characteristic of cellular metabolism, transcription and signaling, apoptosis, response to stress, and the interferon response were all correlated with nicotine exposure. These results strongly suggest that tobacco use promotes a pro-carcinogenic environment, predisposing individuals to develop cancers in a variety of organ systems.

Interestingly, some genes that have previously been linked to smoking were not differentially expressed in our 2 subject groups [61-63]. For example, neither CYP1B1 (a cyto- chrome P450 enzyme playing an important role in chemical carcinogenesis) nor SOD2 (which destroys toxic radicals normally produced within cells) had an expression profile that differed significantly between high and low cotinine groups. Although several previous reports identified these genes as being affected by smoking, design and subject pool differences used in the present study could explain the absence of these genes from our profile. CYP1B1 is expressed to a greater degree in the females than in males and our data set is all male [64]. SOD2 gene expression declines with age [65]. The mean age of one of the studies reporting differential regulation of SOD2 was 27 years while the mean age of our study subjects is 46.5 years, which may explain why the SOD2 


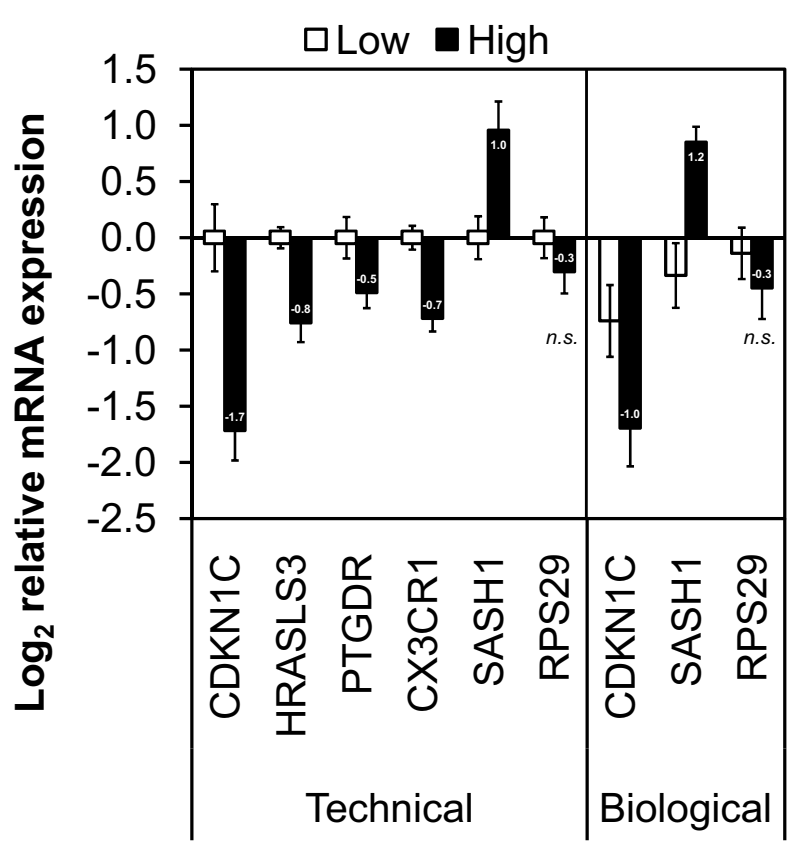

Figure 3

Histogram of relative expression of selected genes using real time PCR. Technical verification (left) of differentially expressed genes identified in the subject population (Caucasian males) by SAM/GSA $(\mathrm{n}=20)$ : CDKNIC, HRASLS3, PTGDR, CX3CRI, and SASHI. Biological verification (right) of two selected genes using independent samples not included in our subject population (Caucasian females, $\mathrm{n}=10$ ): CDKNIC and SASHI. Data is represented as the log base 2 relative change in gene expression ( \pm standard error) and all expression normalized to low cotinine from the subject population samples (Caucasian males). The data labels represent the fold change in high versus low cotinine samples, all of which were statistically significant $(P<0.05)$. The fold change in the gene RPS29 was used as a negative control and was not significant (n.s.) between the high and low cotinine groups.

gene expression ratios between the groups in our study did not vary significantly.

A significant link has been established between smoking and the development of blood-borne cancers such as acute myelogenous leukemia (AML) and acute lymphocytic leukemia (ALL) [66,67]. Exposure to compounds derived from tobacco use is typically highest in the oral and nasal cavities, the laryngotracheobronchial tree, and the urinary system, putting these tissues at the greatest risk of developing tumors [68]. Nevertheless, given chronic exposure to carcinogens, blood tissues are likewise at an increased risk of carcinogenesis [69]. Sandler, et al., observed a clear dose response to smoking, with heavy smokers at the highest risk of developing leukemia [66]. The causative mechanism for this observed increase in leukemia among smokers is unknown. Our results identify highly relevant, differentially expressed genes that may serve as the basis for future experiments aimed at addressing the molecular etiology of AML and ALL in smokers. Moreover, these gene signals were detected in an easily obtainable sample of peripheral blood.

We found a correlation between tobacco use and increased expression of interferon-inducible genes in circulating leukocyte populations. Strong induction of interferon-responsive gene expression was seen in only a subset of tobacco-using subjects, arguing that interferon induction is not a direct effect of tobacco use. The mechanism of induction of these genes is not clear from our data. Previous studies have found a strong correlation between the parenchymal destruction associated with end-stage emphysema and the presence of interferon and interferon-inducible genes in the lung [60]. Intriguingly, 5 of the 6 subjects $(83 \%)$ with a diagnosis of COPD in this study demonstrated the high-interferon response phenotype. Our observation of elevated peripheral interferon response gene expression may reflect a systemic manifestation of a destructive pulmonary inflammatory response. These observations may provide evidence of a systemic immune basis for smoking-related lung parenchymal destruction. Alternatively, the expression of interferonresponsive genes in the periphery may be secondary to the upper and lower respiratory tract infections to which smokers are prone.

Hyperclustering revealed 5 distinct, physiologically relevant gene groups in peripheral leukocytes affected by tobacco use in vivo. Furthermore, these gene groups belong to pathways and regulatory systems important to the etiology of smoking-related diseases. These novel results enhance our understanding of how tobacco use affects patterns of gene expression in leukocytes, and provide a starting point for elucidating the molecular mechanisms of tobacco-related neoplasia, atherosclerosis, and immune dysfunction. The hyperclustering visualization facilitated interpretation of microarray data by fusing the expression data with functional annotation derived through robust statistical methodology (GSA and GATHER) prior to cluster analysis. This technique is a visual representation that combines gene expression data and any form of additional annotation. Gene expression profiling of readily obtainable peripheral blood samples identified genes that regulate response to stress, macromolecular metabolism, transcription and signaling, interferon response, and cell death and resistance to apoptosis. This profile may identify some novel targets for therapeutic intervention for both smoking-related diseases and, potentially, for smoking cessation. 


\section{Competing interests}

The authors declare that they have no competing interests.

\section{Authors' contributions}

PCC participated in design of the study, recruited subjects, processed samples, analyzed data, performed statistical analysis, and participated in manuscript preparation. BA recruited subjects, analyzed data, and participated in manuscript preparation. EGH processed samples, analyzed data, assisted in statistical analysis, and participated in manuscript preparation. JCS assisted in statistical analysis and manuscript preparation. REL participated in study design and coordination, and assisted in manuscript preparation. SM processed samples. JSP assisted in study design and data management. SSW participated in study coordination and recruited patients. AP assisted with manuscript preparation. GAS participated in study design and coordination, and data analysis. CP conceived of the study, participated in study design and coordination, performed data analysis, and participated in manuscript preparation.

\section{Additional material}

\section{Additional file 1}

Principle component analysis (PCA) of subject co-morbidities. PCA was performed using the combined significant gene list and visualized in the context of COPD, Diabetes, CAD class, and smoking status. As expected, the top component of variation is associated with smoking status. Additionally, it does not appear associated with the remaining variables. To formally test this hypothesis, the PC1 loadings were tested for association with each of the 4 clinical variables. Smoking status was found to be significantly associated with PC1 $(p<0.001)$. However, none of the remaining clinical variables were associated with the top component of variation (COPD $p=0.91$; $C A D p=0.15$; Diabetes $p=0.55)$ indicating that this gene list is not strongly associated with these disease states.

Click here for file

[http://www.biomedcentral.com/content/supplementary/17558794-1-38-S1.pdf]

\section{Additional File 2}

Complete gene list of 109 genes identified by SAM and GSA. Differentially expressed genes identified by SAM and GSA demonstrate the up-regulation of 34 genes and the down-regulation of 75 genes in subjects with high versus low plasma cotinine. The table includes the gene symbol, gene name, Genbank Accession ID, Agilent Probe ID and the mean fold change in gene expression in high versus low plasma cotinine subjects. Click here for file

[http://www.biomedcentral.com/content/supplementary/17558794-1-38-S2.xls]

\section{Acknowledgements}

This study was supported in part by an American Heart Association Scientist Development Grant $(0635100 \mathrm{~N})$ to PCC, grants from the NIH (HL072347), CDC ( $\mathrm{H75} / \mathrm{CCH} 424675$ and $\mathrm{H75} / \mathrm{CCH} 424677)$, and UNC School of Medicine ("Investments in the Future" program) to CP, and a Doris Duke Charitable Foundation Fellowship to BDA. C.P. is an estab- lished investigator of the American Heart Association, and a Burroughs Wellcome Fund Clinician Scientist in Translational Research.

\section{References}

I. Goldsmith ZG, Dhanasekaran N: The microrevolution: applications and impacts of microarray technology on molecular biology and medicine (review). International journal of molecular medicine 2004, I3(4):483-495.

2. Fan C, Oh DS, Wessels L, Weigelt B, Nuyten DS, Nobel AB, van't Veer LJ, Perou CM: Concordance among gene-expressionbased predictors for breast cancer. The New England journal of medicine 2006, 355(6):560-569.

3. Seo D, Ginsburg GS, Goldschmidt-Clermont PJ: Gene expression analysis of cardiovascular diseases: novel insights into biology and clinical applications. Journal of the American College of Cardiology 2006, 48(2):227-235.

4. Napoli C, Lerman LO, Sica V, Lerman A, Tajana G, de Nigris F: Microarray analysis: a novel research tool for cardiovascular scientists and physicians. Heart (British Cardiac Society) 2003, 89(6):597-604.

5. Tuomisto TT, Binder BR, Yla-Herttuala S: Genetics, genomics and proteomics in atherosclerosis research. Annals of medicine 2005, 37(5):323-332.

6. Liew CC, Ma J, Tang HC, Zheng R, Dempsey AA: The peripheral blood transcriptome dynamically reflects system wide biology: a potential diagnostic tool. The Journal of laboratory and clinical medicine 2006, I47(3): I26-I32.

7. Burczynski ME, Twine NC, Dukart G, Marshall B, Hidalgo M, Stadler WM, Logan T, Dutcher J, Hudes G, Trepicchio WL, Strahs A, Immermann F, Slonim DK, Dorner AJ: Transcriptional profiles in peripheral blood mononuclear cells prognostic of clinical outcomes in patients with advanced renal cell carcinoma. Clin Cancer Res 2005, I I (3): I I8I- I I89.

8. Alberg AJ, Samet JM: Epidemiology of lung cancer. Chest 2003, I 23(I Suppl):2 IS-49S.

9. Patino WD, Mian OY, Kang JG, Matoba S, Bartlett LD, Holbrook B, Trout HH 3rd, Kozloff L, Hwang PM: Circulating transcriptome reveals markers of atherosclerosis. Proceedings of the National Academy of Sciences of the United States of America 2005, I 02(9):3423-3428.

10. Bennett L, Palucka AK, Arce E, Cantrell V, Borvak J, Banchereau J, Pascual V: Interferon and granulopoiesis signatures in systemic lupus erythematosus blood. The Journal of experimental medicine 2003, I97(6):7II-723.

II. Njolstad I, Arnesen E, Lund-Larsen PG: Smoking, serum lipids, blood pressure, and sex differences in myocardial infarction. A I2-year follow-up of the Finnmark Study. Circulation 1996, 93(3):450-456.

12. Qiao Q, Tervahauta M, Nissinen A, Tuomilehto J: Mortality from all causes and from coronary heart disease related to smoking and changes in smoking during a 35-year follow-up of middle-aged Finnish men. European heart journal 2000, 2 I (19): I62I-1626.

13. Edwards R: The problem of tobacco smoking. BMJ (Clinical research ed) 2004, 328(7433):217-219

14. Tobacco use among adults - United States, 2005. Mmwr 2006, 55(42): I | 45- | | 48.

15. Buttner P, Mosig S, Funke H: Gene expression profiles of T lymphocytes are sensitive to the influence of heavy smoking: A pilot study. Immunogenetics 2007, 59(I):37-43.

16. van Leeuwen DM, Gottschalk RW, van Herwijnen $\mathrm{MH}$, Moonen EJ, Kleinjans JC, van Delft JH: Differential gene expression in human peripheral blood mononuclear cells induced by cigarette smoke and its constituents. Toxicol Sci 2005, 86(I):200-210.

17. Ryder MI, Hyun W, Loomer P, Haqq C: Alteration of gene expression profiles of peripheral mononuclear blood cells by tobacco smoke: implications for periodontal diseases. Oral microbiology and immunology 2004, I9(I):39-49.

18. Lampe JW, Stepaniants SB, Mao M, Radich JP, Dai H, Linsley PS, Friend $\mathrm{SH}$, Potter JD: Signatures of environmental exposures using peripheral leukocyte gene expression: tobacco smoke. Cancer Epidemiol Biomarkers Prev 2004, I 3(3):445-453.

19. Harvey BG, Heguy A, Leopold PL, Carolan BJ, Ferris B, Crystal RG: Modification of gene expression of the small airway epithe- 
lium in response to cigarette smoking. Journal of molecular medicine (Berlin, Germany) 2007, 85(I):39-53.

20. Heguy A, O'Connor TP, Luettich K, Worgall S, Cieciuch A, Harvey BG, Hackett NR, Crystal RG: Gene expression profiling of human alveolar macrophages of phenotypically normal smokers and nonsmokers reveals a previously unrecognized subset of genes modulated by cigarette smoking. Journal of molecular medicine (Berlin, Germany) 2006, 84(4):3 I 8-328.

21. Lodovici M, Luceri C, De Filippo C, Romualdi C, Bambi F, Dolara P. Smokers and passive smokers gene expression profiles: correlation with the DNA oxidation damage. Free radical biology \& medicine 2007, 43(3):4I5-422.

22. Maunders H, Patwardhan S, Phillips J, Clack A, Richter A: Human bronchial epithelial cell transcriptome: gene expression changes following acute exposure to whole cigarette smoke in vitro. American journal of physiology 2007, 292(5):LI 248-I 256.

23. Alcorta D, Preston G, Munger W, Sullivan P, Yang J], Waga I, Jennette JC, Falk R: Microarray studies of gene expression in circulating leukocytes in kidney diseases. Exp Nephrol 2002, 10(2): I39-149.

24. Feezor RJ, Baker HV, Mindrinos M, Hayden D, Tannahill CL, Brownstein BH, Fay A, MacMillan S, Laramie J, Xiao W, Moldawer LL, Cobb JP, Laudanski K, Miller-Graziano CL, Maier RV, Schoenfeld D, Davis RW, Tompkins RG, Inflammation and Host Response to Injury, LargeScale Collaborative Research Program: Whole blood and leukocyte RNA isolation for gene expression analyses. Physiological genomics 2004, 19(3):247-254.

25. Feezor RJ, Cheng A, Paddock HN, Baker HV, Moldawer LL: Functional genomics and gene expression profiling in sepsis: beyond class prediction. Clin Infect Dis 2005, 4I(Supp 7): S427-435

26. Novoradovskaya N, Whitfield ML, Basehore LS, Novoradovsky A Pesich R, Usary J, Karaca M, Wong WK, Aprelikova O, Fero M, Perou CM, Botstein D, Braman J: Universal Reference RNA as a standard for microarray experiments. BMC Genomics 2004, 5(I):20.

27. Cronin M, Ghosh K, Sistare F, Quackenbush J, Vilker V, O'Connell C: Universal RNA reference materials for gene expression. Clin Chem 2004, 50(8): |464-|47|.

28. UMD: [http://genome.unc.edu]

29. Smyth GK, Speed T: Normalization of CDNA microarray data. Methods 2003, 3 I(4):265-273

30. Tusher VG, Tibshirani R, Chu G: Significance analysis of microarrays applied to the ionizing radiation response. Proceedings of the National Academy of Sciences of the United States of America 200I, 98(9):5I|16-5I2I.

31. Storey JD, Tibshirani R: Statistical methods for identifying differentially expressed genes in DNA microarrays. Methods Mol Biol 2003, 224: 149-157.

32. $\mathrm{Yu} \mathrm{H}, \mathrm{Gao}$ L, Tu K, Guo Z: Broadly predicting specific gene functions with expression similarity and taxonomy similarity. Gene 2005, 352:75-81.

33. Eisen MB, Spellman PT, Brown PO, Botstein D: Cluster analysis and display of genome-wide expression patterns. Proc Natl Acad Sci USA 1998, 95: | 4863-|4868.

34. Cluster [http://rana.lbl.gov/EisenSoftware.htm]

35. Saldanha Aj: Java Treeview - extensible visualization of microarray data. Bioinformatics (Oxford, England) 2004, 20(I7):3246-3248.

36. JavaTreeview [http://sourceforge.net/projects/jtreeview/]

37. Subramanian A, Tamayo P, Mootha VK, Mukherjee S, Ebert BL, Gillette MA, Paulovich A, Pomeroy SL, Golub TR, Lander ES, Mesirov JP: Gene set enrichment analysis: a knowledge-based approach for interpreting genome-wide expression profiles. Proceedings of the National Academy of Sciences of the United States of America 2005 , 102(43): I $5545-15550$.

38. Efron B, Tibshirani R: On Testing the Significance of Gene Sets. Stanford Biostatistics Department; 2006.

39. Subramanian A, Kuehn H, Gould J, Tamayo P, Mesirov JP: GSEA-P: a desktop application for Gene Set Enrichment Analysis. Bioinformatics (Oxford, England) 2007, 23(23):325I-3253

40. The Gene Ontology [http://www.geneontology.org/]

4I. Ashburner M, Ball CA, Blake JA, Botstein D, Butler H, Cherry JM, Davis AP, Dolinski K, Dwight SS, Eppig JT, Harris MA, Hill DP, IsselTarver L, Kasarskis A, Lewis S, Matese JC, Richardson JE, Ringwald M, Rubin GM, Sherlock G: Gene ontology: tool for the unification of biology. The Gene Ontology Consortium. Nat Genet 2000 25(I):25-29.
42. Chang JT, Nevins JR: GATHER: a systems approach to interpreting genomic signatures. Bioinformatics (Oxford, England) 2006, 22(23):2926-2933.

43. GATHER- Gene Annotation To Help Explain Relationships.

44. Matys V, Fricke E, Geffers R, Gössling E, Haubrock M, Hehl R, Hornischer K, Karas D, Kel AE, Kel-Margoulis OV, Kloos DU, Land S, Lewicki-Potapov B, Michael H, Münch R, Reuter I, Rotert S, Saxel H, Scheer M, Thiele S, Wingender E: TRANSFAC: transcriptional regulation, from patterns to profiles. Nucleic acids research 2003, 3 I (I):374-378.

45. Matys V, Kel-Margoulis OV, Fricke E, Liebich I, Land S, Barre-Dirrie A, Reuter I, Chekmenev D, Krull M, Hornischer K, Voss N, Stegmaier $P$, Lewicki-Potapov B, Saxel $H$, Kel AE, Wingender E: TRANSFAC and its module TRANSCompel: transcriptional gene regulation in eukaryotes. Nucleic acids research 2006:DI08-II0.

46. Wingender E, Chen X, Fricke E, Geffers R, Hehl R, Liebich I, Krull M, Matys V, Michael H, Ohnhäuser R, Prüss M, Schacherer F, Thiele S, Urbach S: The TRANSFAC system on gene expression regulation. Nucleic acids research 200I, 29(I):28I-283.

47. TransFac [http://www.biobase-international.com/pages/ index.php?id=transfac]

48. Lee KM, Kim JH, Kang D: Design issues in toxicogenomics using DNA microarray experiment. Toxicology and applied pharmacology 2005, 207(2S):200-208.

49. Cowling DW, Johnson TP, Holbrook BC, Warnecke RB, Tang $\mathrm{H}$ Improving the self reporting of tobacco use: results of a factorial experiment. Tobacco control 2003, I2(2): I78- I83.

50. Baron-Epel O, Haviv-Messika A, Green MS, Kalutzki DN: Ethnic differences in reported smoking behaviors in face-to-face and telephone interviews. European journal of epidemiology 2004, 19(7):679-686.

51. Payne CE, Southern SJ: Urinary point-of-care test for smoking in the pre-operative assessment of patients undergoing elective plastic surgery. J Plast Reconstr Aesthet Surg 2006, 59(II):II56-II6I.

52. Bramer SL, Kallungal BA: Clinical considerations in study designs that use cotinine as a biomarker. Biomarkers 2003, 8(34): $187-203$.

53. Wells AJ, English PB, Posner SF, Wagenknecht LE, Perez-Stable E): Misclassification rates for current smokers misclassified as nonsmokers. American journal of public health 1998, 88(10): $1503-1509$.

54. Recillas-Targa F, De La Rosa-Velazquez IA, Soto-Reyes E, Benitez-Bribiesca L: Epigenetic boundaries of tumour suppressor gene promoters: the CTCF connection and its role in carcinogenesis. Journal of cellular and molecular medicine 2006, I0(3):554-568.

55. Torrano V, Chernukhin I, Docquier F, D'Arcy V, Leon J, Klenova E, Delgado MD: CTCF regulates growth and erythroid differentiation of human myeloid leukemia cells. The Journal of biological chemistry 2005, 280(30):28|52-28|6|.

56. Rimkus C, Martini M, Friederichs J, Rosenberg R, Doll D, Siewert JR, Holzmann B, Janssen KP: Prognostic significance of downregulated expression of the candidate tumour suppressor gene SASHI in colon cancer. British journal of cancer 2006, 95(10): $1419-1423$

57. Barlic J, Zhang Y, Foley JF, Murphy PM: Oxidized lipid-driven chemokine receptor switch, CCR2 to CX3CRI, mediates adhesion of human macrophages to coronary artery smooth muscle cells through a peroxisome proliferator-activated receptor gamma-dependent pathway. Circulation 2006, I | 4(8):807-8|9.

58. Rothbarth K, Spiess E, Juodka B, Yavuzer U, Nehls P, Stammer H, Werner D: Induction of apoptosis by overexpression of the DNA-binding and DNA-PK-activating protein CID. Journal of cell science 1999, I I 2(Pt | 3):2223-2232

59. Barry WT, Nobel AB, Wright FA: Significance analysis of functional categories in gene expression studies: a structured permutation approach. Bioinformatics (Oxford, England) 2005 2I(9): 1943-1949.

60. Grumelli S, Corry DB, Song LZ, Song L, Green L, Huh J, Hacken J, Espada R, Bag R, Lewis DE, Kheradmand F: An immune basis for lung parenchymal destruction in chronic obstructive pulmonary disease and emphysema. PLOS medicine 2004, I (I):e8. 
61. Chang TK, Chen J, Pillay V, Ho JY, Bandiera SM: Real-time polymerase chain reaction analysis of CYPIBI gene expression in human liver. Toxicol Sci 2003, 7 I (I): II-19.

62. Port JL, Yamaguchi K, Du B, De Lorenzo M, Chang M, Heerdt PM, Kopelovich L, Marcus CB, Altorki NK, Subbaramaiah K, Dannenberg A): Tobacco smoke induces CYPIBI in the aerodigestive tract. Carcinogenesis 2004, 25( I I):2275-228I.

63. van Leeuwen DM, van Agen E, Gottschalk RW, Vlietinck R, Gielen M, van Herwijnen $\mathrm{MH}$, Maas LM, Kleinjans JC, van Delft JH: Cigarette smoke-induced differential gene expression in blood cells from monozygotic twin pairs. Carcinogenesis 2007, 28(3):69I-697.

64. Finnstrom N, Ask B, Dahl ML, Gadd M, Rane A: Intra-individual variation and sex differences in gene expression of cytochromes P450 in circulating leukocytes. The pharmacogenomics journal 2002, 2(2): III-II6.

65. Tatone C, Carbone MC, Falone S, Aimola P, Giardinelli A, Caserta D, Marci R, Pandolfi A, Ragnelli AM, Amicarelli F: Age-dependent changes in the expression of superoxide dismutases and catalase are associated with ultrastructural modifications in human granulosa cells. Molecular human reproduction 2006 I 2(II):655-660.

66. Sandler DP, Shore DL, Anderson JR, Davey FR, Arthur D, Mayer RJ, Silver RT, Weiss RB, Moore JO, Schiffer CA, Wurster-Hill DH, Mclntyre OR, Bloomfield $C D$ : Cigarette smoking and risk of acute leukemia: associations with morphology and cytogenetic abnormalities in bone marrow. Journal of the National Cancer Institute 1993, 85(24): 1994-2003.

67. Lichtman MA: Cigarette smoking, cytogenetic abnormalities, and acute myelogenous leukemia. Leukemia 2007, 2I(6): II37-II 40

68. Newcomb PA, Carbone PP: The health consequences of smoking. Cancer. The Medical clinics of North America 1992, 76(2):305-33I.

69. Lynge $E$, Anttila A, Hemminki K: Organic solvents and cancer. Cancer Causes Control 1997, 8(3):406-419.

70. Gene Set Enrichment Analysis [http://www.broad.mit.edu/gsea/ ]

71. MSigDB Death_Pathway [http://www.broad.mit.edu/gsea/ msigdb/cards/DEATHPATHWAY.html]

72. MSigDB METASTASIS_ADENOCARC_DN [http:// www.broad.mit.edu/gsea/msigdb/cards/ METASTASIS ADENOCARC DN.html]

73. MSigDB DAC_IFN_BLADDER_UP [http://www.broad.mit.edu/ gsea/msigdb/cards/DAC IFN BLADDER UP.html]

\section{Pre-publication history}

The pre-publication history for this paper can be accessed here:

http://www.biomedcentral.com/1755-8794/1/38/prepub
Publish with Biomed Central and every scientist can read your work free of charge

"BioMed Central will be the most significant development for disseminating the results of biomedical research in our lifetime. "

Sir Paul Nurse, Cancer Research UK

Your research papers will be:

- available free of charge to the entire biomedical community

- peer reviewed and published immediately upon acceptance

- cited in PubMed and archived on PubMed Central

- yours - you keep the copyright 